\title{
Systems thinking, spirituality and Ken Wilber Beyond New Age
}

$\mathrm{S}$

ystems thinking is a general worldview concerning the nature of reality. It sees the world as composed of systems, and all particular entities populating reality as linked with other entities - the emergence of new properties denies the flatland of plain materiality, and generates entities of a higher order. Spirituality in historical and modern traditions has minimally amounted to relating oneself to a larger or higher systemic whole, which confers meaning to particular cases of existence. In some religious traditions this larger systemic whole has been understood as a transcendental sphere of existence, whereas in other religious and spiritual traditions it has been seen as an immanent thatness. The search for spirituality and wisdom has never been confined to religious traditions, but has inspired other systems thinkers as well, for example in philosophy, the New Age movement, in developmental psychology, biology, or futures research. The American philosopher and theoretical psychologist Ken Wilber (b. 1949) has discussed, re-interpreted and synthesized various views on spiritual development as well as systems thinking and has provided input for the New Age movement, comparative religion, developmental psychology, and world philosophy. In this article we will discuss the relationship between systems thinking and spirituality and will assess Ken Wilber's contribution to their conceptualization.

\section{Introduction}

We will start with working definitions for systems thinking and spirituality. Both systems thinking and spirituality are projects in understanding the world in terms of connectedness, wholes and parts. Systems thinking is a tool of thought used in different branches of science, management and futures research (Bunge
1979). It is typically inspired by science and ontological materialism, even though there are systems thinkers who have adopted idealistic ontology (see, e.g., Radhakrishnan 1932). The interesting potential in systems thinking, no matter whether it is based on materialistic or idealistic ontology, is that it can provide tools for analysing and bridging the distinction between the material and the ideal.

We understand spirituality as a conceptual framework, a way of seeing the world as an interconnected whole, where different parts of the world are permeated by the same intelligible logic or same material out of which different appearances are made. As Mary N. MacDonald aptly summarizes her synoptic working definition of spirituality:
Spirituality is the concern of human beings with their appropriate relationship to the cosmos. How the cosmic whole is conceived and what is considered appropriate in interacting with it differ according to worldviews of individuals and communities. Spirituality is also con- strued as an orientation toward the spiritual as distinguished from the exclusively material. (MacDonald 2005: 8718)

We add that spirituality is therefore primarily a type of consciousness involving a conceptual framework, a worldview, that structures the world into 'reality' and 'appearance' and invites one to search for lawful connections that, first of all, link the perceptible phenomena and the reality behind the appearances, and secondly, govern the dynamics of the ultimate reality (Elkins et al. 1988). As a form of consciousness that relates appearances and reality, spirituality is a way of situating the self in the 
Eeva Kallio, <https://www.flickr.com/photos/donnaceleste/albums>

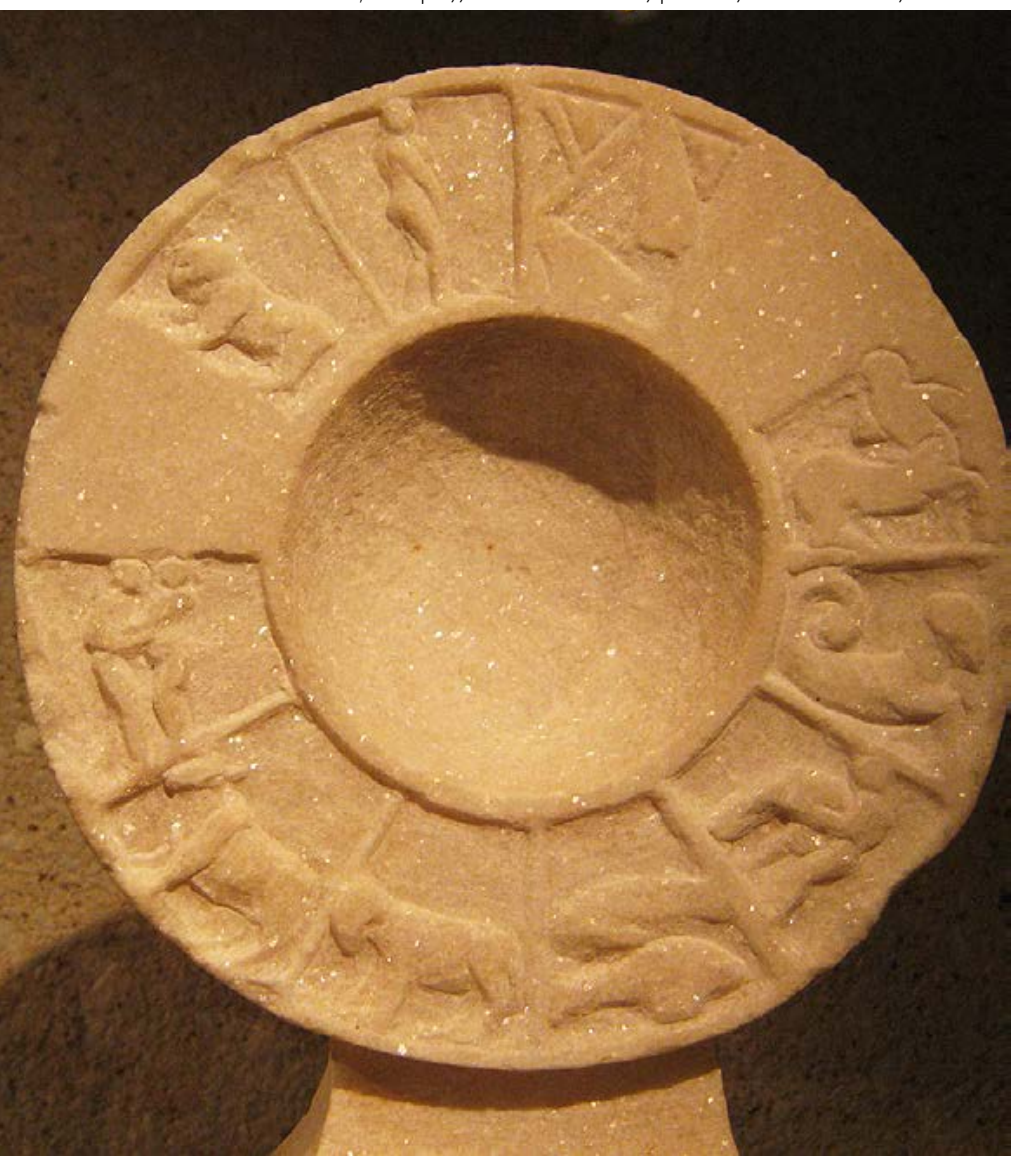

Neues Museum, Berlin.

world. Spirituality denies the flatland of materiality, acknowledges the depth of reality and sees the layers of reality (cf. Hill et al. 2000).

Spirituality in this relaxed sense covers a large collection of worldviews ranging from philosophical and scientific to mystical, mythical and religious, expert views and vernacular folk theoretical conceptualizations of the world. These traditions differ from each other for example in restricting the group of people who may have access to the reality, and whether the access requires certain techniques on the part of the practitioner (meditation, devotion, mystical intuition, ecstasy, experimentation or rational inference), and whether the access to the spiritual requires the cultivation of a particular counterpart in humans, that is, the spirit. The study of these cultural forms of spirituality is a study of the diversity of human thinking, and it combines comparative religion and worldview studies, as well as the study of world philosophies (Smart 2000, Hammer 2001).

The various spiritual traditions of different ages and cultures have become available to contemporary Western consumers, and this trend has manifested itself especially in the New Age movement, where the various cultural resources of different spiritual traditions have been recruited for the purpose of 'celebrating the self and sacralizing modernity' (Heelas 1996, Hanegraaff 1996). The primary New Age movement, best symbolized perhaps by Fritjof Capra (1975) has been superseded by a multiplicity of spiritualities, and the cultural scene has moved beyond New Age, as aptly described by Steven Sutcliffe and Marion Bowman (2000). The uniting theme in various forms of spirituality is the worldview component we proposed above, namely, the search for a systemic order and the explanation or experience of interconnectedness, where the flatland of one-dimensional materiality is transcended. We admit that there are various other aspects to spirituality, for example its psychological, sociological, economical or historical aspects, but for our purpose the focus on spirituality as a conceptual framework serves the task.

\section{World philosophy in the study of spiritualities}

Comparative religion that purports to investigate different spiritualities is bound to accommodate philosophy in two roles: as its study object and as an analytic tool for the following reasons. First of all, spirituality is a conceptual framework, performing the task of relating oneself to the world, and the analysis of conceptual frameworks requires the analytic tools of philosophy. Secondly, in the cultures of India and China, from where several spiritual traditions stem, the division of labour between religion, philosophy and empirical science is not so clearly articulated as it is in Western university culture. Together these cognitive endeavours address the big questions of what we are, where we are going, how we know and what is of value. Furthermore, it has been claimed that there are culturally specific nonWestern philosophical traditions that are optimal for analysing the religions of their respective cultures Hindu or Taoist philosophy, for example. All in all, the scholar in comparative religion should have competence in philosophy as well.

Ninian Smart (2000) has proposed that there exists philosophical articulation and construction of worldviews in different traditions, not only in the written traditions of China, India and the West, but also in the oral wisdom and traditional folklore of different cultures. The description and analysis of these philosophical worldviews is what Smart calls 'world 
philosophy'. He intends to reveal the plural character of human consciousness, and uses three themes in the description and analysis of the material: wisdom (spiritual, political or ethical), worldview (metaphysical, scientific or religious), and the theme of critic and questioner (ibid. 6).

If we follow Smart, world philosophy (as a tool of philosophically enlightened comparative religion) should be descriptive and culturally sensitive. The philosophy in this tradition resembles good ethnography, where the worldviews or belief systems of various culturally situated study objects are investigated by means of interpretative hypotheses. The goal of the research process is the articulated worldview. The shared core of world philosophy and ethnography, vital for comparative religion, is the Socratic method: you ask the informant about his beliefs and desires, and in the course of this exchange the informant (as well as the interviewer) is able to articulate his point of view. The Socratic method is used also in some therapies, where the patient is facilitated in seeing things from a new perspective. Ethnographic interview techniques are partially beholden to philosophical question-setting and the philosophers working in other cultures borrow techniques from ethnography. Descriptive world philosophy and standard descriptive ethnography also share the goal of neutral description.

Other 'world philosophers' like Ben-Ami Scharfstein (1998) restrict the scope of world philosophy to those written traditions of India, China and Europe that embrace the signs of philosophy: logic (or wellarticulated reasoning) and disputation, where the analytic tools of thought and rules of argumentation are applied to solve the questions. If we follow Scharfstein in conducting world philosophy, our stance is more normative and the scope is more limited. According to Scharfstein, we should be interested in those texts and informants who provide articulated reasons for their beliefs. According to Scharfstein, we are also warranted to ask for reasons, and to assess beliefs and practices in terms of their acceptability, because philosophical analysis is inherently normative: it values clarity and exposition of axiomatic principles, and in the course of analysis and exposition, it brings out the weaknesses of the system under analysis.

We think that Ninian Smart's conception of world philosophy is more fruitful for comparative religion since its major tone is descriptive and interpretative, not critical. Comparative religion based on ethnography and other fields of research that utilize cultural analysis profit from the mastery of philosophical tools, since the analysis of culturally conditioned conceptual systems and of cultural informants requires that they are treated with Socratic, philosophical interest. Both ethnographers and philosophers are entitled to ask trivial questions, to question given assumptions and make inferences concerning the required pieces of knowledge left unarticulated in the daily practices they encounter. Both ethnography and philosophy aim at reconstructing the conceptual systems under analysis so that their structures become transparent. Both are needed in comparative religion, which aims at analysing contemporary spiritualities. Next we will analyse systems thinking and then proceed to Ken Wilber's contribution.

\section{Systems thinking}

Spirituality as a form of consciousness constructs the world as a systemic whole, where different parts are interconnected. Thus at the heart of spirituality lies systems thinking in one form or other. Systems thinking is a general view concerning the nature of reality. It sees the world as composed of systems, and all particular entities populating the reality as linked with other entities (Kamppinen 2010).

A system is a collection of components that are linked with each other. For example, a shamanistic healing session in the Peruvian Amazon is a system that is composed of patients and healers and medical artifacts, and it interacts with the rest of the village that, in turn, is situated in a larger system of ecological systems (Kamppinen 2010). To individuate a system is to draw boundaries around some components, and construe the other components as the environment in which the system is embedded. The healing session, for example, is interacting with its environment, and we have a case of a system that is linked to other components.

The original system and its environment can be linked or 'summed up' in order to form a larger system, for example the village. In a sense, the first division between a system $s 1$ and its environment e1 always implies the existence of a larger system $s 2$ that is composed of $s 1$ and $e 1$. The resulting system $s 2$ can be analysed in terms of its environment $e_{2}$, and again we have the possibility of linking $s 2$ and $e 2$ into a supersystem $s 3$. 
The notions of level, emergent novelty and hierarchy are central in systems thinking (cf. Bunge 1979). The level can be defined as a collection of similar entities. As we move from the level of individual patients to the level of healing session, new properties emerge, for example the patient-healer interactions, or the success of healing. These properties do not exist at the level of individual patients, but emerge only as we move to more complex systems that involve patients, healers and the healing tools as components. Emergent novelty denies the onedimensional existence of flatland.

Furthermore, as we move up to the level of healing session, emergent systemic entities like classifications of illness appear. Complex systems like healing sessions involve different types of hierarchies. Constitutive (or bottom-up) hierarchy refers to the way in which the components of the healing session make up the whole, whereas regulative (or topdown) hierarchy refers to the ways in which higherlevel entities like healers' mental models regulate the processes at lower levels. The individual action of expelling evil spirits, for example, can be situated in both hierarchies. In constitutive hierarchy it enables the healing session to go on, whereas in regulative hierarchy it fulfils a role in the shamanistic healing scene, a role that has been determined from the top.

The notion of multiple realizability (or one-tomany correspondence) is central to systems thinking as well, since it is grounded on the notion of regulative hierarchy. Multiple realizability means that higher-level entities can be implemented in various configurations of lower-level entities. A healing session, for example, can be constructed in various ways: the patients and illnesses may vary, the proportions of plant medicines and other concrete healing techniques may vary, and so on. Village level health behaviour can be implemented in various ways as well. It can involve all members of the village or leave some of them out, or it can be driven by legislation or by the traditional mental models of religious experts like shamans. There are, of course, some structural and functional requirements for what counts as a case of health behaviour in the first place but in general higher-level entities allow for multiple realizations.

Even though higher-level entities can be realized multiple compositional solutions, they are dependent on lower-level entities. Higher-level entities such as a soccer game between villages cannot exist without individual villages and their constituents, or health values do not exist without evaluating human agents.

Douglas Hofstadter (1979: 307) illustrates an

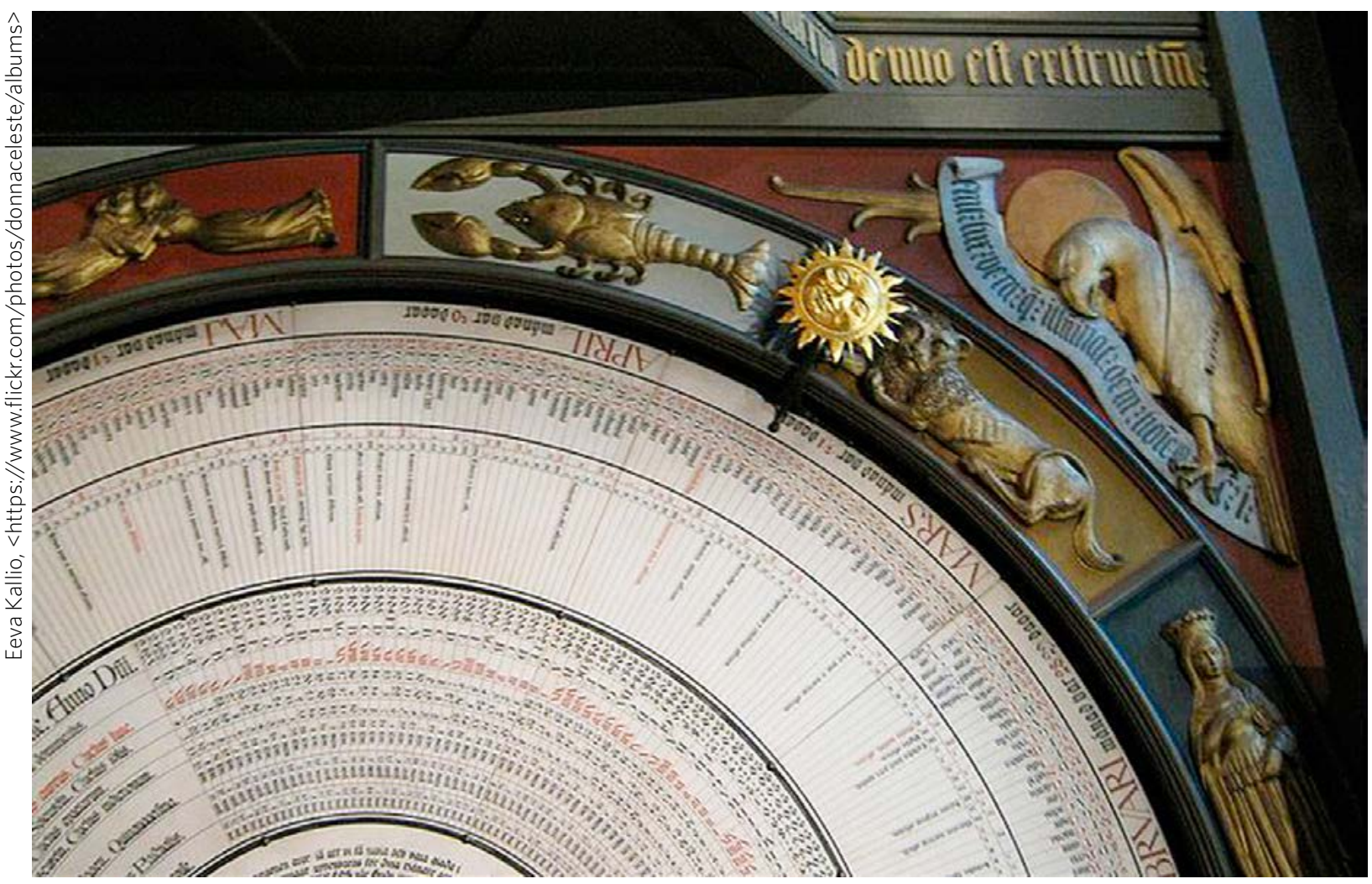

A detail of an astronomical clock, Lund Cathedral, Sweden. 
important distinction. There are first of all systems where changes at a lower level do not bring about noticeable changes at the higher level. The higher-level system is stable, even though, for example, one patient fails to show up and is replaced by another patient. Another type of dependence is a case of a rumour spreading from one patient to another which claims that the healer is incompetent. The rumour culminates in a situation where a new healer is searched for and found. In this case the lower-level changes bring about significant changes at a higher level.

For the classics of systems thinking such as that of Ludwig von Bertalanffy (1969) the systems view was essentially a general empirical theory based on induction: we observe that the world is composed of interrelated, complex entities that are only partially studied by specific scientific disciplines. Bertalanffy envisioned a future of ever more technological and scientific complexity, and therefore he predicted that the need for systems thinking 'generalists' would grow. Bertalanffy was a philosopher and a biologist, and the core exemplars for his systems thinking came from these disciplines.

Management science has made remarkable and readable contributions to systems thinking. In a sense it is easy to see why this is, since managers need to take into account complex systems connected to different organizational levels - or expect to see the business go bankrupt. Peter Checkland (1999) integrated human actors into complex systems and emphasized the role of rule-following yet innovative agents in the creation, sustenance and modification of systems. His socalled 'Soft Systems Methodology' is a set of blueprints by means of which different actors can understand, create and control systemic structures.

Futures research, on the other hand, has produced similar, agent-centred constructs. Creating a desirable future and avoiding undesirable ones requires that actors participate consciously in the creation and control of systems (Slaughter 2012). Peter Senge managed to present and articulate systems thinking in his The Fifth Discipline (1990). Simple examples of beer markets and hand-drawn illustrations provide the reader with an understanding of systems mechanisms such as reinforcing feedback, balancing process and delay. Senge's writings have attracted followers from various fields of research and development: technology, education science, nursing, architecture, and humanities (see also Hämäläinen and Saarinen 2007, 2008).
Ervin Laszlo (1996) is another pioneer of systems thinking who envisioned a world where not only scientists share the systems view of the world, but other cultural actors as well: religions should celebrate the evolutionary self-creation of the universe, and recognize that 'the self-creating universe is our larger self - our primary sacred community' (Laszlo 1996: 90).

\section{Science and systems thinking}

The scientific enterprise can be seen as the latest and perhaps the most powerful tool in understanding the world, and its success is based on the fundamental assumption that the world as we perceive it should be distinguished from and explained by the reality behind the appearances. The search for systems characterizes the scientific enterprise, as Nicholas Rescher writes:

The emergence of lawful order in a world of chance and chaos is a natural and rationally tractable phenomenon. Throughout the sciences ... there is emerging a common recognition that a universe of chance and chaos is not unruly (anarchic) but merely complex, exhibiting through its natural operation the emergence of higher-order lawfulness. (Rescher 1998: 206)

The search for systems in the scientific enterprise has been crystallized in mathematical physics, where the formulae are used to describe the lawful functioning of the material universe. In biology, the same driving force was illustrated in the Biomorph programme that accompanied Richard Dawkins' book The Blind Watchmaker (1987): in the Biomorph programme, one could generate complex patterns starting from simple constituent and rules. Biological complexity stems from algorithmic mechanisms, simple elements and rules (Dennett 1995). An early precursor of the Biomorph was John Conway's Game of Life (1970), in which simple rules generated complex patterns that appeared to compete with each other for spatial resources. Stephen Wolfram's New Kind of Science (2002) presented a general theory of cellular automata where complex patterns could be generated from simple algorithms. Also the projects of Albert-Laszlo Barabasi (2003) and John Holland (1995) have searched for the algorithmic systems behind the appearance of complexity. 


\section{Emergence and spirituality}

The emergence of complexity and novelty is central in systems ontology, and the formation of a corresponding type of consciousness, able to grasp higherlevel entities, is a feature in systems thinking. The practitioners of different spiritualities and scientists investigating the systems of the world thus share some common tools of systems thinking. Yet there are certain differences: spiritualities using the resources of religious traditions are typically committed to idealistic ontology as well as to common sense methodologies, whereas science commits itself to materialistic ontology and rigorous testing of hypotheses. Another putative difference has been that religion-based spiritualities are dealing with awe-inspiring, inexhaustible wholes, whereas science tends to be more tedious than inspiring.

Scholars working on emergence, especially biological systems, have come to change this. Stuart Kauffman claims that the material, system-structured world filled with emergent properties, is the new sacred, the proper object of our spiritual aspirations:

In this view, much of what we have sought from a supernatural God is the natural behavior of the emergent creativity in the universe. If one image can suffice, think that all has happened for 3.8 billion years on our planet, to the best of our knowledge, is that the sun has shed light upon the Earth, and some other sources of free energy have been available, and all that live around you has come into existence, all on its own. I find it impossible to realize this and not be stunned with reverence. (Kauffman 2008: 282)

A similar point has been made by Edward O. Wilson, when he tries to explain the immense value of biodiversity to a fictional Pastor, a literal believer of Holy Scriptures:

Do you agree, Pastor, that the depth and the complexity of living Nature still exceed human imagination? If God seems unknowable, so too does most of the biosphere. Biologists never cease to stress how little we understand of the living world around us. (Wilson 2006: 15)

The complexity of the real world generates novelty, the emergence of things that were not there before. For many scholars and science-minded lay people, this provides enough material for awe, reverence and sacredness. The emergent properties of human beings and social systems are also stunning as they provide a basis for talking about higher levels of consciousness as natural phenomena. Thus spirituality as a type of postformal consciousness that embraces wisdom as one of its assets can also be seen in naturalistic terms, as an emergent feature of human beings.

\section{Ken Wilber and systems thinking}

The American philosopher Ken Wilber (b. 1949) is a perfect example of what it means to move beyond New Age. Wilber started with cross-cultural transpersonal psychology and moved into world philosophy. He has been inspired by developmental psychology, Eastern and Western varieties of psychological development, Indian philosophers like Sri Aurobindo Ghose, Western philosophers like Plotinus or Hegel, studies in comparative religion and world philosophy, and has contributed to the respective fields as well. Wilber has been characterized as a multitalented theorist in transpersonal psychology and world philosophy, a critic of postmodern culture, a perennialist, a Western pandit or 'spiritual intellectual, and a mystic, who has experienced alternative states of consciousness (Visser 2003: 40-2).

Wilber is a 'perennialist' in a very special sense, namely that he aims at identifying not only perennial philosophy (a common worldview core of different traditions), but also perennial psychology, namely the shared cross-cultural models of the human mind. Wilber is a systems-builder aiming at a holistic or integral view of world, a spiritual view that honours different cultural traditions and their aspirations in providing an overall understanding of how oneself is situated in the world. Taking Wilber's basic aim into account, it is understandable that systems thinking pervades his work (Combs 2009).

In what follows we will discuss Wilber's contribution to the discussion of how systems thinking and spirituality are related. We will not go into a critical assessment of Wilber's thinking, but will rather identify and highlight some interesting openings in his writings. The dual nature of criticism directed against Wilber's writings is interesting, though. Others have proposed that Wilber's writings do not line up with scientific or philosophical traditions (Meyerhoff 2010). And they are right. Others have claimed that Wilber does not acknowledge frankly enough his 
debt to particular religious traditions, Theosophy or Buddhism (Visser 2003, Ferrer in this volume). And they are right, too. But we will proceed with systems thinking and spirituality.

Indeed, systems thinking is one of the constant features in Wilber's writings. In his first book The Spectrum of Consciousness (1977) he had already constructed human consciousness as a system where different levels emerge as their constituents come into place. Developmental processes such as maturing, the construction of identity, or attaining wisdom, are examples of emergence, in which novel properties act back upon the constituent system and change the system of consciousness. Wilber's particular contribution was to combine perspectives from different psychological and philosophical models, and show how the models of development of Western psychology and Eastern religion-based psychologies complement each other and enable one to construct an integral model of human development that includes not only cognitive and emotional development, but also spiritual, mystic and transpersonal experiences. Human psychological development is a kind of evolutionary process, where the emerging structures are built upon the earlier layers of development, and the development does not come to halt at the stage of formal operations, as has been taught on courses of Western psychology. The specific contribution of Eastern religion-based psychologies is in providing an account of those levels of spiritual experience that transcend some of the categories of Western psychology.

The systemic view of human consciousness where emergent properties and new levels of existence are generated remained Wilber's basic model of any area of development, be it psychological, social or cultural. Accordingly, in his subsequent books such as The Atman Project (1980) and Up From Eden (1981) Wilber treated not only the psychological development of individuals, but also social evolution. There he followed the philosopher-anthropologist Jean Gebser (1986) who had compared individual and social lines of development and had argued that psychological competences are tailored to, or conditioned by, social formations. Wilber argued that just as there are levels of psychological development, there are levels of social and cultural development. More to the point, Wilber argued already in his early writings that evolutionary progress would not come to halt in the culture of modernity or post-modernity, nor in the psychological level of formal operations or reflec-

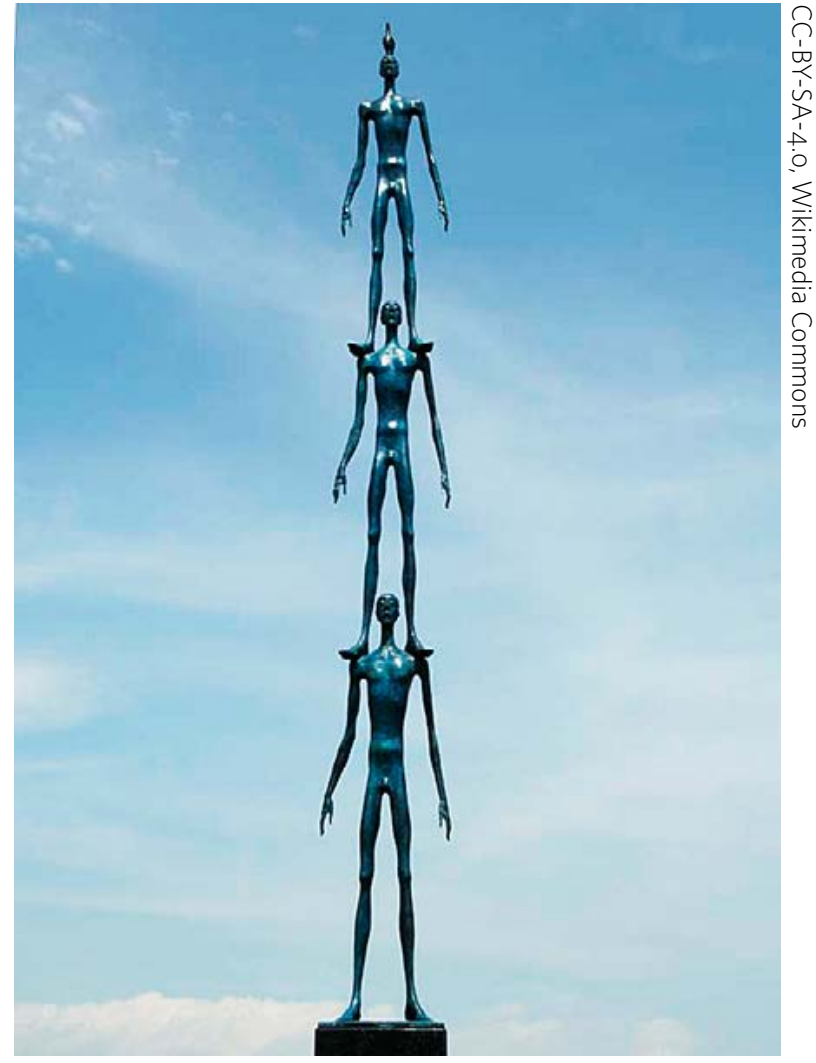

Meditation by Dimitry Gerrman, 1999.

tive morality. Emergent evolution, both individual and social, would proceed beyond what we have in our current societies: higher forms of consciousness would emerge as the relevant developmental requirements come into place: the overall mental and cultural evolution would not stop in the context of postindustrial consumer culture.

Wilber's evolutionary account would need a background theory, and in his major work Sex, Ecology, Spirituality: The Spirit of Evolution (1995) he proposed the theory of part/whole structures or holons in order to provide the foundations for his view of emergent evolution. Holons are entities that constitute part/whole hierarchies (or holarchies), and they can be seen as parts (that constitute wholes) or as wholes (that can be decomposed into parts). The world is made of holons, or entities that participate in the networks of parts and wholes. The human being, for example, is simultaneously a material, mental and social holon, composed of material parts and mental states, participating in social interactions and so on (Karlsson and Kamppinen 1995). An individual thought is composed of mental content and psychological mode, and it participates in thinking and other mental or behavioural processes (cf. Minsky 1985). 
The concept of the holon provided the much needed systems theoretical foundations for Wilber. In Sex, Ecology, Spirituality, Wilber also proposed his 'All Quadrants, All Levels' model (the AQAL model) for conceptualizing different phenomena. According to the AQAL model, all entities, but especially human beings, exist in mental, material, individual and collective holarchies, and in order to have an integral model of human development, one should understand the four quadrants and their characteristic levels and lines of development. In short, Wilber's systems thinking amounts to a denial of the flatland; the denial of a one-dimensional material world order. It accommodates the world of systems or of holons, where the lower levels of reality combine and interconnect to generate higher levels of order, higher entities not known at the lower levels.

Wilber claims that his holonic view is different from what he calls standard systems thinking because systems thinking ignores the internal perspective, the first-person experience. Wilber (2006) dismisses even systems thinkers like Fritjof Capra (1997) and Ervin Laszlo (2007), claiming that their systems views involve forms of subtle reductionism, the assumption that treats all entities as material entities. Both Capra and Laszlo are science-oriented, and they aim at integrating different fields of knowledge from that perspective. In the final analysis, Wilber's systems thinking is based on the assumption that entities are pervaded by the spirit, and hence he commits himself to an idealistic ontology.

\section{The systemic features of spirituality}

In Wilber's worldview, spirituality has two faces. On one hand, it resides in human beings as a psychological potentiality, as an attitude towards the world. On the other hand, it is in the systemic character of the world, the systemicity that makes the holistic attitude plausible.

On the psychological side, according to Wilber, spirituality shows itself in different parts of psychological development. Wilber (2000a) distinguishes five different aspects of spirituality: 1) Spirituality involves the highest levels of any of the developmental lines, that is, the highest cognitive capacities, most developed affects and moral aspirations, the most evolved self and so on. 2) Spirituality is the sum total of the highest levels of the developmental lines. 3) Spirituality is itself a developmental line. 4) Spirituality is an attitude (such as openness or world-centric love) that you can have at whatever stage you are at. 5) Spirituality basically involves peak experiences. Wilber argues that all five aspects should be taken into account when investigating or cultivating spirituality. It is evident that spirituality as a human property is a systemic feature that emerges from mental structures and builds upon previous development.

Another face of spirituality that Wilber is committed to is that the mental contents involved in spirituality posit the world as a systemic whole, as an interconnected supersystem that is permeated by what Wilber calls the Spirit. Spirituality in the psychological sense makes sense only if the world has certain systemic features. Experiencing the unity and interconnectedness of the world is valid only if the world in some sense has these properties. Spirituality transcends the flatland, not only in the human subject, but also in the world that is experienced. And as we argued above, in Wilber's thinking, this systemicity is based on idealistic ontology, the fundamental perspective according to which everything that is, is ultimately spirit, or form. Spirit shows itself in the pattern or organization of matter, when material entities are connected to each other.

\section{Practice and spirituality}

This far we have looked at spirituality and systems thinking in general and in Wilber's thinking as they both postulate the interconnected level-structure of the world. That is, we have looked at both of them from the theoretical or intellectual perspective, aiming at describing and understanding their mutual dependencies. The practical perspective is quite another matter, as Wilber writes:

In the East, as well as in the West, there tend to be two rather different approaches to spirituality - that of the scholar and that of the practitioner. The scholar tends to be abstract, and studies world religions as one might study bugs or rocks or fossils - merely another field for the detached intellect. The idea of actually practicing a spiritual or contemplative discipline rarely seems to dawn on the scholar. (Wilber 1989: xiii)

In several places, Wilber argues that the possible benefits of spiritual practices like those of meditation 


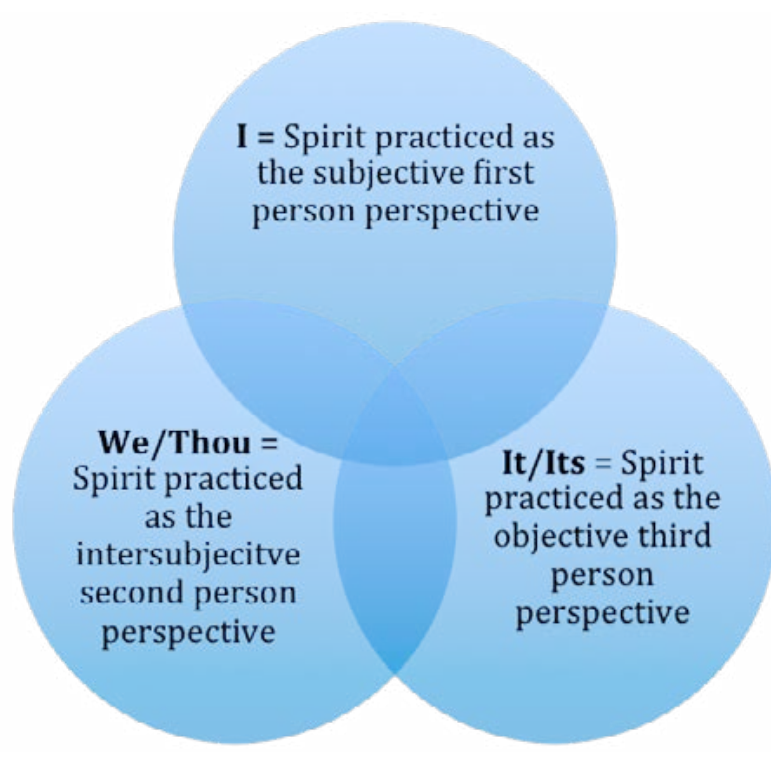

The Big Three of Spiritual Practice (adapted from Wilber 2006).

can be rigorously studied by means of experimenting with the practice.

This is in line with Wilber's overall integral approach. Since, according to the integral model, everything is a tetra-emergent holon, everything must then be understood from the inside out and outside in. It is not sufficient to view spirituality exclusively from the objective, third person perspective; it must also be experienced from the first person perspective, at least to a degree, in order to gain integral understanding of the subject. An integral approach to spiritual practice requires, then, both theoretical comprehension and practical experience. Systems thinking as a framework for spirituality requires a methodology, a way, a meta hodos, by which we arrive at certain vistas (Wilber 2001a, 2007b).

Wilber offers a concept to clarify this. In what he calls the 'One-Two-Three of Spirit', he argues how Spirit can be understood through three different perspectives (Wilber 2007a: 159-61). These perspectives correlate with the Big Three, as explained in, for example, Sex, Ecology, Spirituality.

The Big Three (or ' $1-2-3$ of God') is Wilber's attempt to conceptualize the different approaches to spiritual experience, practice and typology. The first person perspective on spiritual practice might take the form of meditation; a second person perspective may be contemplative prayer; third person perspective may be a form of pantheism or, even, deep systemic thinking, as exemplified in Kauffman (2008). What is common to all three practice-perspectives is that they all are enacted upon, and made into emergent realities of being, by following a certain set of injunctions. Hence, 'Spirit practised as'.

Wilber also views certain spiritual methodologies as spiritual sciences, if science is taken to mean the three strands of knowledge accumulation. What is common to these traditions of knowledge accumulation is that they involve 1) instrumental injunction, 2) intuitive apprehension, and 3) communal affirmation. If so, then the purer schools of certain spiritual paths such as Zen, Gnostic Christianity or Sufism, can be called scientific as they follow the basic structure of scientific inquiry. (Wilber 2001b: 40-58)

Practice can be seen as a first-person experience of what is postulated from the third-person perspective as the emergent nature of an interconnected systems view. It is an attempt to gain phenomenological experience, by a certain method, of what is comprehended by the abstract intellect. It is an experiment for which conceptual thinking creates the framework, which is then, in a sense, filled out by the practitioner's first-person phenomena, the gradual modification or evolution of which are regulated by the particular method or lineage used for the practice (i.e., Zen Buddhist zazen; Gurdjieff's Work; Vajrayana Buddhist visualisation techniques; sufist $z i k r$; etc.). This filling out of the contents of consciousness by the means of spiritual practice forms the essential core of practical, experiential spirituality.

Further, Wilber offers classification schemes and practical injunctions for the various levels and types of spiritual experience. The big three of spiritual practices (fig.) is firstly; the Wilber-Combs Lattice with the ambitious goal of classifying every possible spiritual experience by using the worldview level/ altitude as the Y-axis, and (secondly) the depth of the experience as the $\mathrm{X}$-axis (Combs 2009: 101); the concept of religion as a conveyor belt is the third (Wilber 2007a: 193). We will briefly look into the idea of the conveyor belt, on which Wilber writes:

This is perhaps the most important role for religion in the modern and postmodern world, acting as a sacred conveyor belt for humanity. ... [W] hile honoring the myths, one must move from myth to reason to trans-reason in order to plumb the depths of spiritual realities. That is, one must allow the line of spiritual intelligence to continue its growth from amber [Piaget's 


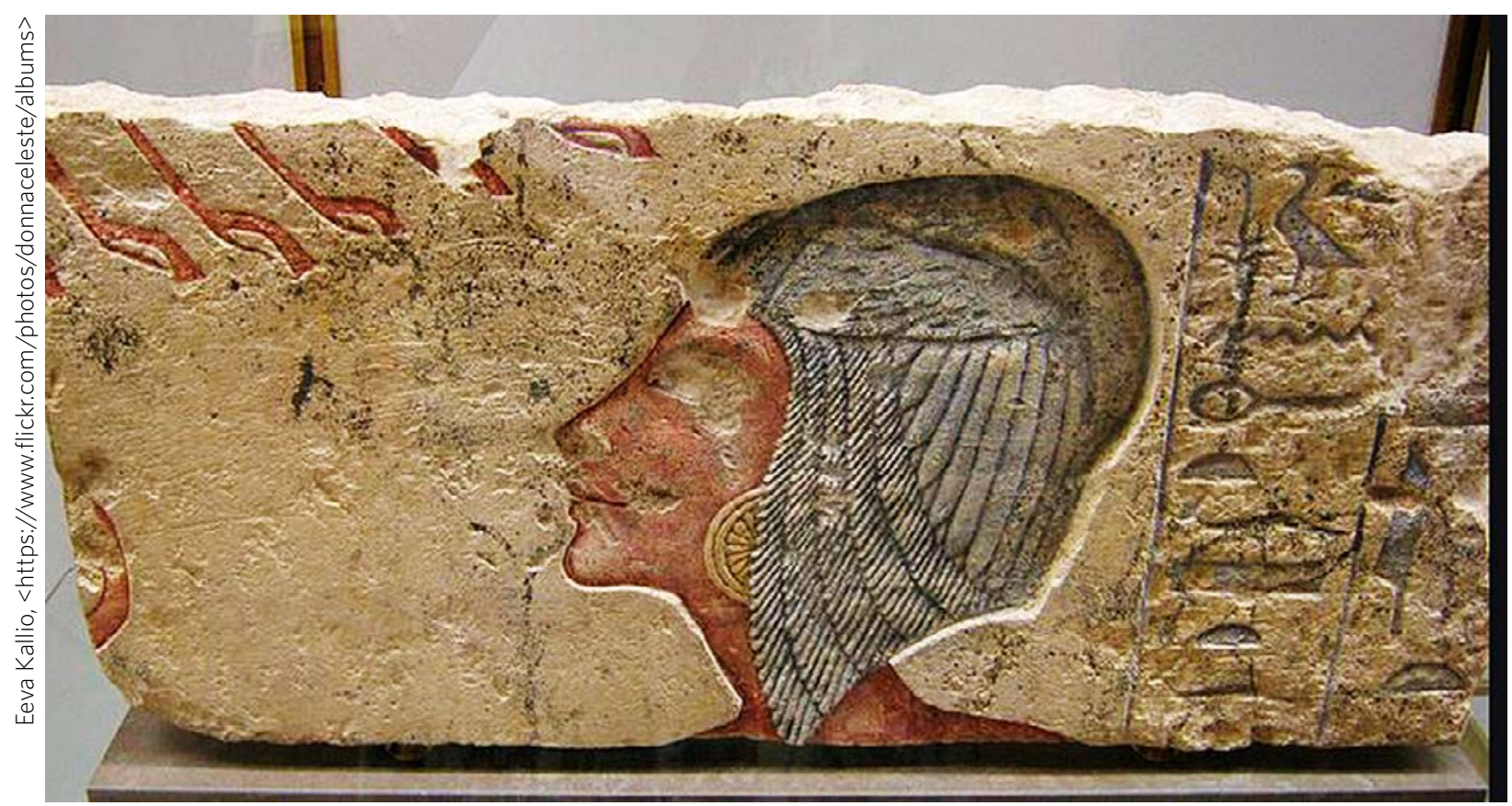

Glyptoteket, Copenhagen.

concrete-operational; Fowler's SyntheticConventional; Ethnocentric] into higher levels ... Honoring, cherishing, and celebrating the myths, definitely; elevating them to absolute reality, definitely not. (Wilber 2007a: 193)

Here we should catch our breath and recapitulate. What Wilber is suggesting is that religions can be liberated from the burden of being closed containers for mythologies no longer relevant for the modern and postmodern and post-postmodern age; but rather opened up from both sides to allow a metaphorical conveyor belt, containing all levels of spirituality, to traverse through them. Religions provide means for transcending the flatland. This conveyor belt allows both the mythological and the rational; both the magical and the trans-rational; both the archaic and the mystical elements of religion to exist and find their proper places in the human consciousness. Suggesting that both science and religion have a fixation on the mythic level of spiritual development, Wilber argues for a framework that allows a more spacious view of the role of science and spirituality in the modern and postmodern world. One of the marks of this framework is seeing religion as the conveyor belt that has the unique ability to carry spiritual development forward.

Seeing religion as an evolutionary force, a conveyor belt, instead of a closed system, helps us to approach religion in a positive light - a light that is, if we may add, quite useful in these dark times where regressive fundamentalism and liberal freedom of speech have collided in destructive ways. This light is further reflected, for example, in philosopher Steve McIntosh's (2015) nuanced argument on fostering evolution in Islamic culture, an issue rarely tackled in mainstream comparative religion due to its normative overtones, but also an issue that can be conceptualized by means of Wilberian tools.

\section{Conclusion}

Ken Wilber provides a challenge for the study of contemporary spiritualities and comparative religion: on one hand, his work is a legitimate object of study, since he frames and facilitates a worldview where spirituality is central. He has adopted influences from various sources such as Western developmental psychology and philosophy, Eastern psychology and philosophy, mysticism and New Age movements. On the other hand, he has contributed not only to developmental psychology, but to world philosophy and comparative religion as well. Thus his project is both the subject and the object of comparative religion, resembling the project of Huston Smith, a scholar in comparative religion, who concluded in his study Forgotten Truth (Smith 1976) that the pre-scientific, primordial traditions shared a spiritual worldview 
that has been dismissed in the flatland of modernity, and that thinning of the world has generated a onedimensional, materialistic world.

Evolutionary systems thinking is another doublesided issue: most scholars agree that the physical and the biological levels of reality undergo evolutionary changes, where complexity is increased and new phenomena emerge from lower levels. Wilber has argued that emergent evolution, both individual and social, would proceed beyond what we have in our current societies: higher forms of consciousness would emerge as the developmental requirements come into place, and overall mental and cultural evolution would not stop in post-industrial consumer culture. Different forms of spirituality as projects for transcending the flatland of one-dimensional materiality provide ample materials for future research in the field of comparative religion.

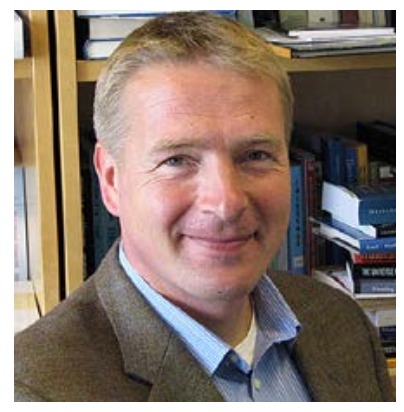

Matti Kamppinen is Professor of Comparative Religion at the Department of History, Cultural Research and Arts Studies at the University of Turku. He has studied Amazonian folk religion, mental models of environmental risks, and philosophical issues in comparative religion. His latest book (together with Pekka

Hakamies) The Theory of Culture of Folklorist Lauri Honko was published by The Edwin Mellen Press in 2013. He has published articles in various journal like Forest Policy and Economics, Method and Theory in the Study of Religion, Technology in Society, Temenos and Futures.

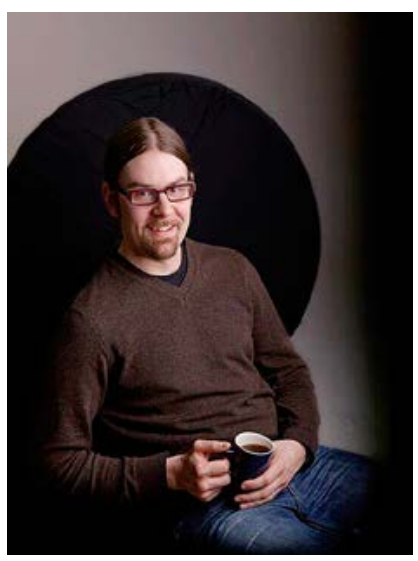

$M A$, independent scholar JP Jakonen is specialized in the practical applications of Integral Theory in leadership development. He is particularly interested in the relationship between the integral model and the good life. Jakonen is a certified Integral Associate Coach $^{\text {TM }}$ and has written three popular books on the Integral Theory as it relates to leadership development and change.

\section{Bibliography}

Barabasi, Albert-Laszlo, 2003. Linked (New York, Plume Book)

Bertalanffy, Ludwig, 1969. General Systems Theory: Foundations, Development, Applications (New York, George Braziller)

Bunge, Mario, 1979. A World of Systems (Dordrecht, Reidel Publishing Company)

Capra, Fritjof, 1975. The Tao of Physics (New York, HarperCollins)

- 1997. The Web of Life (New York, Anchor)

Checkland, Peter, 1999. Systems Thinking, Systems Practice (New York, Wiley)

Combs, Allan 2009. Consciousness Explained Better: Towards an Integral Understanding of the Multifaceted Nature of Consciousness (St. Paul, Paragon House)

Dawkins, Richard, 1987. The Blind Watchmaker (New York, Norton)

Dennett, Daniel C., 1995. Darwin's Dangerous Idea: Evolution and the Meanings of Life (New York, Simon \& Schuster)

Elkins, David N., L James Hedström, Lori L. Hughes. J. Andrew Leaf, and Cheryl Saunders, 1988. 'Toward a humanistic-phenomenological spirituality: definition, description, and measurement', Journal of Humanistic Psychology, 28(4), pp. 5-18

Gebser, Jean, 1986. The Ever-Present Origin (Athens, Ohio University Press)

Hämäläinen, Raimo P., and Esa Saarinen (eds), 2007. Systems Intelligence in Leadership and Everyday Life (Helsinki University of Technology, Laboratory for Systems Analysis)

-(eds), 2008. Systems Intelligence: A New Lens on Human Engagement and Action (Helsinki University of Technology, Laboratory for Systems Analysis)

Hammer, Olav, 2001. Claiming Knowledge: Strategies of Epistemology from Theosophy to the New Age (Leiden, Brill)

Hanegraaff, Wouter, 1996. New Age Religion and Western Culture: Esotericism in the Mirror of Secular Thought (Leiden, Brill)

Heelas, Paul, 1996. The New Age Movement: The Celebration of the Self and the Sacralization of Modernity (Oxford, Blackwell)

Hill, Peter C., Kenneth I. Pargament, Ralph W. Hood Jr, Michael E. McCullouch, Lames P. Swyers, David B. Larson, and Brian J. Zinnbauer, 2000. 'Conceptualizing religion and spirituality: points of commonality, points of departure, Journal for the Theory of Social Behaviour, 30(1)

Hofstadter, Douglas, 1979. Gödel, Escher, Bach: Eternal Golden Braid (New York, Basic Books)

Holland, John, 1995. Hidden Order: How Adaptations Builds Complexity (New York, Basic Books)

Kamppinen, Matti, 2010. Intentional Systems Theory as a Conceptual Framework for Religious Studies (Lewiston, The Edwin Mellen Press)

Karlsson, Hasse, and Matti Kamppinen, 1995. 'Biological 
psychiatry and reductionism: empirical findings and philosophy', The British Journal of Psychiatry, 167, pp. 434-8

Kauffman, Stuart 2008. Reinventing the Sacred: A New View of Science, Reason, and Religion (New York, Basic Books)

Laszlo, Ervin, 1996. The Systems View of the World (New York, Hampton Press)

-2007. Science and the Akashic Field (Rochester, Inner Traditions)

MacDonald, Mary N., 2005. 'Spirituality' in Encyclopedia of Religion, 2nd edn, ed. Lindsay Jones (Detroit, MacMillan)

McIntosh, Steve, 2015. Fostering Evolution in Islamic Culture (Boulder, Institute for Cultural Evolution), $<$ http://www.culturalevolution.org/docs/ICE-Fostering-Evolution-in-Islam-White-Paper.pdf $>$ (accessed 24.3.2015)

Meyerhoff, Jeff, 2010. Bald Ambition: A Critique of Ken Wilber's Theory of Everything (LaVerne, Inside the Curtain Press)

Minsky, Marvin, 1985. The Society of Mind (New York, Simon \& Schuster)

Radhakrishan, Sarvepalli, 1932. An Idealist View of Life (London, Georg Allen \& Unwin)

Rescher, Nicholas, 1998. Complexity: A Philosophical Overview (New Brunswick, Transaction Publishers)

Scharfstein, Ben-Ami, 1998. A Comparative History of World Philosophy (Buffalo, SUNY Press)

Senge, Peter, 1990. The Fifth Discipline (New York, Currency Doubleday)

Slaughter, Richard A., 2012. To See with Fresh Eyes: Integral Futures and the Global Emergency (Indooroopilly, Foresight International)

Smart, Ninian, 200o. World Philosophies (London, Routledge)

Smith, Huston, 1976. Forgotten Truth (New York, Harper)

Sutcliffe, Steven, and Marion Bowman (eds), 2000. Beyond New Age: Exploring Alternative Spirituality (Edinburgh University Press)

Visser, Frank, 2003. Ken Wilber: Thought as Passion (Albany, SUNY Press)

Wilber, Ken, 1989. 'Foreword' to Georg Feuerstein, Yoga: The Technology of Ecstasy (New York, P. Tarcher), xiii-xiv

- 1993 (1977). The Spectrum of Consciousness, 2nd edn (Wheaton, Quest Books)

-1995. Sex, Ecology, Spirituality: The Spirit of Evolution (Boston, Shambhala)

-1996a (1980). The Atman Project: A Transpersonal View of Human Development, 2nd edn (Wheaton, Quest Books)

-1996b (1981). Up From Eden: A Transpersonal View of Human Evolution, 2nd edn (Wheaton, Quest Books)

-2000a. Integral Psychology: Consciousness, Spirit, Psychology, Therapy (Boston, Shambhala)

-20oob. A Theory of Everything: An Integral Vision for Business, Politics, Science and Spirituality (Boston, Shambhala) -2001a. The Eye of Spirit: An Integral Vision for a World Gone Slightly Mad (Boston, Shambhala)

-2001b. Eye to Eye: The Quest for the New Paradigm, 3rd edn, revised (1983) (Boston, Shambhala)

-2006. 'Spirituality that transforms' in What Is Enlightenment?, ed. Andrew Cohen, <http://www.kenwilber. com/Writings/PDF/ASpiritualitythatTransforms_ GENERAL_b420oo.pdf> (accessed 12.12.2013)

-2007a. Integral Spirituality: A Startling New Vision for Religion in the Modern and Postmodern World (Boston, Integral Books)

-2007b. The Integral Vision: A Very Short Introduction to the Revolutionary Integral Approach to Life, God, the Universe, and Everything (Boston, Shambhala)

Wilson, Edward O., 2006. The Creation: An Appeal to Save Life on Earth (New York, Norton)

Wolfram, Stephen, 2002. A New Kind of Science (Champaign, Wolfram Media) 